\title{
Article
}

\section{Conceptualisations of children's wellbeing at school: the contribution of recognition theory}

Thomas, Nigel, Graham, Anne, Powell, Mary Ann and Fitzgerald, Robyn

Available at http://clok.uclan.ac.uk/12656/

Thomas, Nigel ORCID: 0000-0002-5310-9144, Graham, Anne, Powell, Mary Ann and Fitzgerald, Robyn (2016) Conceptualisations of children's wellbeing at school: the contribution of recognition theory. Childhood, 23 (4). pp. 506520. ISSN 0907-5682

It is advisable to refer to the publisher's version if you intend to cite from the work. http://dx.doi.org/10.1177/0907568215622802

For more information about UCLan's research in this area go to http://www.uclan.ac.uk/researchgroups/ and search for < name of research Group>.

For information about Research generally at UCLan please go to http://www.uclan.ac.uk/research/

All outputs in CLoK are protected by Intellectual Property Rights law, including Copyright law. Copyright, IPR and Moral Rights for the works on this site are retained by the individual authors and/or other copyright owners. Terms and conditions for use of this material are defined in the policies page.

\section{CLoK}

Central Lancashire online Knowledge www.clok.uclan.ac.uk

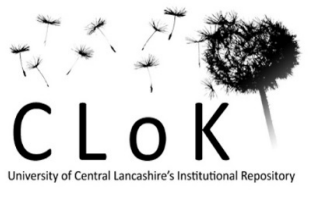




\title{
Conceptualisations of children's wellbeing at school: the contribution of recognition theory
}

\author{
Authors: Nigel Thomas ${ }^{1}$, Anne Graham ${ }^{2}$, Mary Ann Powell ${ }^{2}$, Robyn Fitzgerald ${ }^{2}$ \\ ${ }^{1}$ The Centre for Children and Young People's Participation, University of Central \\ Lancashire, UK; Centre for Children and Young People, Southern Cross University, \\ NSW, Australia. \\ ${ }^{2}$ Centre for Children and Young People, Southern Cross University, NSW, Australia.
}

\section{Corresponding author:}

Nigel Thomas, School of Social Work, Care and Community, University of Central Lancashire, Preston PR1 2HE email: npthomas@uclan.ac.uk

\section{Keywords:}

student wellbeing, recognition theory, schools, children, relationships

\begin{abstract}
:
A large study in Australian schools aimed to elucidate understandings of 'wellbeing' and of factors in school life that contribute to it. Students and teachers understood wellbeing primarily, and holistically, in terms of interpersonal relationships, in contrast to policy documents which mainly focused on 'problem areas' such as mental health. The study also drew on recognition theory as developed by the social philosopher Axel Honneth. Results indicate that recognition theory may be useful in understanding wellbeing in schools, and that empirical research in schools may give rise to further questions regarding theory.
\end{abstract}




\section{Introduction}

Children's wellbeing is an increasingly important area of interest for policy and research. Schools in particular have been identified as critically important sites for promoting students' wellbeing in a number of countries, including the UK, Ireland and Australia (Aggleton et al., 2010; Fattore et al., 2007; Hamilton and Redmond, 2010; Munn, 2010; Sixsmith et al., 2007; Watson et al., 2012). In Australia, the focus of this article, schools are now widely considered to be the 'logical - if not the only common, assured delivery point for wellbeing initiatives' (ASPA, 2008: 2). Recent policy initiatives, such as the Melbourne Declaration on Educational Goals for Young Australians (MCEETYA, 2008) and the National Safe Schools Framework (DEEWR, 2011), indicate that improving the wellbeing of children and young people is a key policy priority for Australian governments (Redmond, Skattebol and Saunders, 2013).

While wellbeing is a 'very appealing notion' (Amerijckx and Humblet, 2014: 404) and hence widely appropriated as a way of capturing our aspirations for children and young people, the term itself is often poorly defined and under-theorised (Camfield $e t$ al., 2009; McAuley and Rose, 2010). The majority of the literature on wellbeing is concerned with measurement (Ben-Arieh, 2006; Stratham and Chase, 2010; UNICEF, 2007), and often with economic and other indicators. By contrast, interventions to promote wellbeing in schools tend to be focused on individual circumstances and issues identified as priority concerns for children, especially around mental health and safety (DEEWR, 2011). A review of national, state and local policy frameworks, conducted for the research on which this article is based, showed that this is certainly the case in Australia. Close analysis also reveals that despite the increased attention to wellbeing, there is little specific wellbeing-focused education policy, a lack of conceptual clarity, and a fragmented approach to implementation that is inconsistent with current best-practice knowledge (for detail see Volume 1 of the research report, Graham et al., 2014a).

In recent years more attention has been given to children and young people's own views about wellbeing (Bourke and Geldens, 2007; Redmond et al., 2013; Skattebol et al., 2013; Gillett-Swan, 2014) and to the need for a holistic approach; there is also 
research that shows the importance of relationships at the micro level in promoting students' resilience (Johnson, 2008). The research discussed here starts from these points. The primary aim was to learn directly about how students and teachers understand the concept of 'wellbeing' and what factors they think contribute to 'wellbeing', in order to provide a more grounded orientation for policy and practice in this area. The secondary aim was specifically to test the utility of recognition theory, and in particular Honneth's three modes of recognition (1995), for understanding actors' conceptualisations of wellbeing.

\section{Recognition theory and the position of children}

Theories of recognition are associated principally with the work of Honneth (1995), Taylor (1994) and Fraser (1995). All start from the Hegelian idea that identity is constructed dialogically, through a process of mutual recognition. However, the way in which each uses the concept of recognition is significantly different (see Thompson, 2006). Taylor's concern is with the nature and validity of recognition claims in multicultural societies that include groups with substantially different interests and values. Fraser approaches recognition through a broader emphasis on fairness in the distribution of resources. Honneth's more ambitious project is to build a theory of social progress founded on the concept of recognition as a fundamental element in human interaction and individual and group identity. Honneth has also articulated the concept of recognition in a more complex way than other recognition theorists. It is this articulation, perhaps even more than the overarching theory, that makes his model interesting as a way of thinking about children's position in society (Thomas, 2012).

Honneth (1995) uses a threefold conceptualisation of intersubjective recognition, originally taken from Hegel and for which he finds empirical support in Mead, which he refers to in summary as love, rights and solidarity. By love he means 'primary relationships insofar as they - on the model of friendships, parent-child relationships, as well as erotic relationships between lovers - are constituted by strong emotional attachments among a small number of people' (Honneth, 1995: 95). By rights Honneth refers to the respect for persons implied in modern legal relations, whereby 
'subjects reciprocally recognize each other with regard to their status as morally responsible' (1995: 110). By solidarity Honneth means the outcome of 'social relations of symmetrical esteem' (1995: 129), where an individual's sense of being 'valuable' depends on being recognised for accomplishments that are specifically theirs, but shared, in a differentiated manner, with others. These three dimensions of recognition are phenomenologically coupled with three different aspects of practical self-relation: self-confidence, self-respect and self-esteem (see also Van Den Brink and Owen, 2007).

Honneth generally does not refer to children except in the context of primary relationships of love and care; although he has begun to address this more recently, to some extent (Honneth, 2012a, 2014). This is consistent with 'the default position of much social and political theory, [which] is either to disregard children entirely or to regard them merely as adults-in-waiting' (Thomas, 2012: 458). However, if we start from the premises of the 'new paradigm' of Childhood Studies, then 'children are and must be seen as active in the construction and determination of their own social lives, the lives of those around them and of the societies in which they live' and not merely as 'passive subjects of social structures and processes' (Prout and James, 1990: 8). With these ideas in mind we take the view: that children do belong to the class of morally responsible persons, are rights-bearers and so are entitled to respect; and 'that children are people with talents and capabilities, who contribute in a variety of ways to society and culture and so are deserving of esteem' (Thomas, 2012: 458). These are the assumptions that underpin the use of recognition theory in the research reported here. We follow a number of authors who have used Honneth's theory to understand adult-child relations in a variety of contexts (Fitzgerald et al., 2010; Houston and Dolan, 2008; Thomas, 2012; Warming, 2006), to explore the 'real world' validity of the model through empirically testing the relevance and utility of its concepts.

\section{The 'wellbeing in schools' research}

The aim of this research was to generate new knowledge about wellbeing in schools, with a view to promoting improved outcomes for children and young people. The research was funded by the Australian Research Council under its Linkage 
programme, with active engagement from partners in the field. An advisory group for the research included children and young people as well as key stakeholders from the project partners.

The research followed a mixed methods approach, and was conducted in four successive phases: (1) An analysis of key relevant local, state and Commonwealth policy statements regarding wellbeing $(N=80)$; (2) Semi-structured interviews with principals and teachers $(N=89)$ and focus groups with primary and secondary students $(N=606)$; (3) An online survey with primary students $(N=3,906)$, secondary students $(N=5,362)$ and staff $(N=707)$; (4) Analysis and presentation of findings and professional development work in schools.

Three Catholic school regions (A, B and C), each in a different Australian state, were chosen because they were willing to make a commitment to the research for the duration of the project, had a strong existing engagement with 'pastoral' work which offered fertile ground for the aims of the project, and also offered contrasting approaches to the implementation of wellbeing policy and programs in schools.

Our focus in this paper is on Phase 2 of the research, the qualitative work in schools. Phase 1 revealed a fragmented policy approach to wellbeing, with policy predominantly oriented towards students 'at risk', or mental health and safety concerns, which contrasted with the more holistic account of wellbeing communicated by participants in Phase 2. Phase 3 allowed us to develop a more nuanced enquiry into how the issues identified in Phase 2 affected groups of students and staff differentially. We report on these phases elsewhere, and also in the project report (Graham et al., 2014a, b).

\section{Methods used in Phase 2}

The interviews and focus groups were conducted across the three participating school regions in June and July 2012. Participating schools $(n=18)$ were identified in consultation with the research partners and with Directors of Education from the three 
regions, and approached by letter to the principal inviting participation. Schools were selected to provide a diverse range of sizes and socioeconomic, geographic and cultural characteristics. Once schools had consented to participate in the research, students and teachers were invited to be involved by the school principals or their delegates, in close consultation with the researchers. Letters of invitation outlining the research aims, process, methods and ethical considerations, together with consent forms, were prepared for schools and distributed to teachers, students and their parents or carers.

In each school the researchers requested interviews with the principal and four teachers. Interviews were conducted with 89 staff (18 principals and 71 teachers), seeking their perspectives on wellbeing in schools and on the best approaches to facilitating and supporting wellbeing. Student focus groups were recruited from Years 1 and 2 (aged 6-7), Years 5 and 6 (aged 11-12), Year 8 (aged 14) and Year 11 (aged 17). In total, there were 67 focus groups with 606 students participating, distributed evenly across the four age groups. Focus group methods involved dialogue, drawing, and written texts to elicit rich data concerning how students understand wellbeing and the ways in which it is practised in schools. Participants were invited to respond to open questions in four areas: students' individual definitions of wellbeing; who in their lives they thought influenced their wellbeing; what it felt like to be 'cared for', 'respected' and 'valued' (see below); and finally, to imagine an ideal school that would support their wellbeing.

Interviews and focus groups were audio-recorded and transcribed, combined with additional written notes and drawings by students, and coded and analysed using NVivo software for qualitative data analysis. Ethical approval for the research was granted by the University Ethics Committee and by each of the participating regional education offices where the research was taking place.

\section{Initial exploration of concepts used by students and teachers}

In both student focus groups and teacher interviews, the first objective was to learn what the term 'wellbeing' meant. An open-ended question was therefore asked, 
with the aim of generating rich data that captured understandings of wellbeing without, initially, any reference to concepts linked to recognition theory (see below).

\section{Students' understandings of wellbeing}

Students found the word 'wellbeing' both familiar and strange. Despite having heard the word many times, especially at school, students found it difficult to define:

I know what I am thinking but I don't know how to explain it (C31B $)^{1}$.

Students also noted that the word can be ambiguous. For every definition offered, an inconsistency or contradiction was readily identified. For example, defining wellbeing as 'happiness', which initially met with agreement, would often be subject to deeper inquiry about whether wellbeing could not co-exist with unhappiness.

Students' descriptions of wellbeing fell broadly into categories we identified in our initial analysis as 'being', 'having' and 'doing': for example, being happy, having someone to trust, doing kind things for oneself and others. These three categories provided the basis for a conceptual framework for wellbeing as expressed by the students (Graham et al., 2014a).

Wellbeing was identified as a state of being across multiple dimensions including social and emotional, physical and spiritual, manifested when students felt their needs were being met. Social and emotional wellbeing dominated discussion, frequently contextualised within relationships. Emphasis was placed on trust, connectedness, belonging and being known in relational contexts.

Wellbeing means you're happy where you are (A53A).

Rich in love, treated well, wanted (A43B).

\footnotetext{
${ }^{1}$ The unique identifier following each quote indicates the region (A, B, C), the school code (1-6), the year level (1 - Years 1 and 2; 3 - Years 5 and 6; 8 - Year 8; 11 - Year 11), and which specific group out of the two at that school (A or B).
} 
Wellbeing was discussed in terms of having such things as equality, voice, confidence, respect, support from significant others, privacy and rights.

Everyone is equal....everyone is seen as the same.....there's no one who is higher up than others (A211B).

I think having things forced upon you can make you feel that your decisions don't matter (B58A).

Students' accounts of wellbeing thus included both perceptions of what it is and of factors that contribute to it; Gillett-Swan (2014) suggests that misalignment between these two elements may contribute to the difficulty in defining wellbeing.

The third dimension, wellbeing as doing, appeared when students spoke of their own actions in constituting their wellbeing. These clustered around relational aspects such as looking after oneself, acceptance, making good decisions, acts of kindness.

Students also talked of the absence of wellbeing, and the negative emotions it produced, with depression featuring in the discussions as a possible consequence of absence of wellbeing. Stress and anxiety, in particular, were identified as impacting negatively on student wellbeing.

I guess being cared for makes you feel like you're worthwhile, there is a reason for being here but I guess if you're not cared for, it feels like a continuum and that's when you start to go down the depression path (A28B).

A key underpinning feature across all three dimensions was the relational context. When asked what they felt helped their wellbeing at school, students pointed to a caring family, good friends, caring teachers and a safe and supportive school. As for what got in the way, key factors were bullying, 'yelling' or negative attitudes from teachers, inability to influence unfair school rules, and 'your family not allowing you to make your own mistakes'. 


\section{Teachers' understandings of wellbeing}

Teachers and principals viewed wellbeing as multidimensional, although there was little consensus around the importance of particular dimensions. Accounts referred to emotional, mental, physical, social and spiritual aspects of children's lives. Narratives were interwoven with references to happiness, safety and a holistic approach. While the dimensions encompassed personal, relational and environmental spheres, the dominant aspect for teachers, as for students, was the relational context:

If you don't have a good relationship with the students, you're not going to know about those wellbeing issues (A1TB) ${ }^{2}$.

I think there's a relationship that the teacher builds with a child and your hope as a teacher, your greatest wish, is that you connect with every child (B2TB).

For teachers, dynamics in teacher-student relationships were at the heart of wellbeing. They stressed the importance of students feeling understood and cared about, their individual qualities, talents and differences acknowledged and valued, and of treating all children well, accepting and respecting them.

Teachers also spoke of the importance of communication with students, with an emphasis on listening and hearing:

I think if you're going to look at the wellbeing of the students, the first and foremost thing that needs to be addressed is this; they need to feel understood and therefore you need to communicate with them (A1TB).

Teachers placed strong emphasis on knowing students:

He has flourished in this new school, and he has flourished because - his words are "I'm not invisible; they really know I'm here". (B5TB).

I don't think we can have any clue about wellbeing if we don't... know a student well enough so that when they walk into your classroom and [you] realise "They're a bit down today", "They're a bit flat" or "They're really

\footnotetext{
${ }^{2}$ Similarly to the student codes above, the unique identifier following each quote indicates the region (A, B, C), the school code (1-6), that it was a quote from a teacher (T), and the specific teacher at the school (A, B, C etc.).
} 
excited. What's happened?" If you don't know them well enough then you don't even register that $(\mathrm{C} 2 \mathrm{TF})$.

There are similarities in what students and teachers said regarding conceptualisations of wellbeing: in particular the multidimensional character of wellbeing and the centrality of relationships. A range of relationships were mentioned, but both students and teachers made extensive reference to the student-teacher relationship. Students focused on the importance of being 'known' by teachers and each other, and teachers focused on the importance of 'knowing' students. This leads directly to our second aim, of exploring the potential of recognition theory for advancing the understanding of student wellbeing. We turn now to examine the links between wellbeing and recognition that emerged from our analysis.

\section{Recognition and wellbeing}

For Honneth (2007), a central principle of critical theory is that it must be grounded not in abstract principles but must also have a social foundation. If a theory is to do more than merely appeal to the ethical standards upon which it bases its critique, then it must prove the existence of empirically effective forms of morality upon which it can legitimately build (Honneth, 2007). Challenged by Honneth himself to ensure theory is grounded in social practice, we now describe how we have sought to apply recognition theory to this study in ways that ensure its foundations are built upon the lived everyday experience of those for whom recognition is such a vital concern.

There are many ways in which the data presented above resonate with concepts of recognition. Relationships are of course central to recognition, with acts of recognition and misrecognition, and struggles over recognition, occurring in relational spaces. An emphasis on relationships permeates everything that participants said, and the categories of being, having and doing are not difficult to connect, loosely, with Honneth's three modes of recognition (love, rights and solidarity, respectively). However, when we explicitly introduced these concepts into the focus group discussions, following the initial discussion of how participants understood wellbeing, 
there was an immediate understanding and articulation of their relevance to student concerns.

The concepts were translated into terms that the research team and advisory group believed would be accessible and comprehensible to students including the children in primary school Years 5-6 who participated (with children in Years 1-2 we used different concepts, following a pilot stage). So 'love', 'rights' and 'solidarity' were translated into 'cared for', 'respected' and 'valued', terms which reflect Honneth's core concepts in ways that are readily understood, avoiding the romantic connotations of love or the controversial nature of rights in school settings (Graham et al., 2009). We did not discuss the theory of recognition in depth, but focused simply on the three modes. With students, we said 'Some people think that to achieve wellbeing we need three things: we need to be cared for (for ourselves); we need to be respected (as people); we need to be valued (for what we contribute).' Then we asked them what they thought. With teachers we used the terms 'recognition' and 'theory', but did not go into further detail.

\section{Cared for}

The dimension of cared for was evident in both student and teacher data. ${ }^{3}$ Students described being cared for as foundational to their wellbeing:

The biggest one we think was being loved by others ... you feel very safe and you feel confident within yourself and like you belong (B58A).

Also if no-one cares for you, you can feel like you shouldn't for yourself (A111A).

The cared for dimension was also the most evident of the dimensions in the teacher interviews, teachers appearing more comfortable with this dimension than the other two. Teachers used a range of terms and concepts: love, care for, support, connection, knowing, acknowledging, interest and comfort. Like students, teachers emphasised the importance of students having a sense of belonging and connectedness.

\footnotetext{
${ }^{3}$ For students, 'being loved' was the most constant theme, after happiness, in the being data; and students were less reticent or self-conscious about using the word 'love' than might have been expected.
} 
Both students and teachers emphasised the importance of the care shown to students by teachers being genuine, something over and above their 'job description.' Students felt the key role of teachers in schools was to care for students, through communicating their concerns for student wellbeing, noticing when things are not going well, facilitating opportunities for caring between students, supporting, encouraging and having conversations with students. Teachers' comments suggested that caring must be proactive:

They might just be having an off day and you go "Hang on, what's going on? This isn't normal" and you find out that somebody might have passed away. It's about observation and then acting on that and not letting it go (B1TD).

Central to the discussion of being cared for in relationships, for both groups, was the concept of trust. Students emphasised the importance for their wellbeing of having sufficient confidence to express themselves, including communicating their needs and asking for these to be met:

Some of them you can actually build a personal relationship, and they understand you (C211A).

They're there so you can trust them and talk to them about things (C311A).

\section{Respected}

The dimension of being respected was of core importance for students, who described self-respect, and respect for others, as central to their wellbeing:

Schools show respect by listening (A18A).

Teachers. I care if they respect me (A28B).

The issue of respect was also apparent in students' 'imaginary schools' drawings and narratives; implicit in primary students' depictions and identified explicitly by secondary students (Simmons, Graham and Thomas, 2015). As a general principle, respect was understood by many students as something everyone deserves and which 
should be exercised equally, although this was not always evident in practice or shared by all students.

The importance of respect for student wellbeing was discussed much less by the teachers in the Phase 2 interviews. Instead, it was mainly evident in discussions about the importance of consistently treating students well, regardless of their individual differences. Language and concepts of respect for teachers included having fair expectations, being fair and just, 'following through' and being consistent. However, students identified inconsistencies in their treatment by teachers, principals and schools, which were perceived as a key causal factor for diminishing respect between students and teachers and impacting negatively on their wellbeing. These are discussed further below in relation to misrecognition.

A key contribution of this study is looking at the meaning of 'respect' in everyday life for students in school settings. An important aspect of 'respect' apparent in the data is around students' opportunities for 'having a say' (Anderson and Graham, in press). Mechanisms for student participation and student voice indicate respect for children and young people in exercising their rights. Students in focus groups placed considerable importance on having a say for their wellbeing, identifying it as important for wellbeing during the 'imaginary schools' activity.

It's pretty hard to come across a teacher that really respects and values your opinion; a lot of them they listen to you and they ask your opinion but they don't do anything about it - they just leave it (B611B).

Students and teachers both acknowledged that school culture and structures provide many of the conditions for students to be either respected or disrespected (recognised or misrecognised). As noted above, both students and teachers emphasised that students having a say, expressing themselves and actively participating were key to a sense of belonging in the school community. Students reported that experiences of not having their views valued or acted on made them feel not respected in school. This attests to the centrality of conversation, the vehicle through which student voices are 
heard and responded to, and the cultural or structural conditions necessary for facilitating it.

\section{Valued}

Being valued was less prominent in the student focus group discussions than cared for or respected. Students emphasised accepting themselves and others 'for who they are'. Teachers described structures within school such as 'house' systems in which students were acknowledged and celebrated for their individual differences, abilities and skills.

The connections between and layering across the three modes of recognition in both students' and teachers' data was evident in discussions of students being valued. Students described a sense of collective valuing when they experience all students being treated equally and respectfully. Teachers emphasised being cared for in the sense of belonging and connectedness, as well as feeling valued as members of the group.

\section{Misrecognition}

Recognition is not all about positive experiences. Exclusion, insult, or degradation of the individual or group are acts of misrecognition, which violate self-confidence, selfrespect and self-esteem. Honneth advocates being open to 'hurt feelings', because 'negative emotional reactions' (1995: 135) constitute an 'affective source of knowledge' (1995: 143) and offer insights into the nature of a particular situation and the source of struggle. Struggles over recognition begin with hurt feelings arising from an injustice, which may then motivate collective protest and struggle. Therefore, feelings like shame, humiliation, anger and indignation are important for telling us where the implicit rules of recognition have been violated. Our research captured student experiences in which these feelings were identified.

Students described aspects of school life that had a negative impact on their wellbeing, providing many examples of conditions for misrecognition. Most of this 
coalesced around disrespect, and included actions by teachers such as not listening, making incorrect assumptions about students and their friendship groups, unequal treatment, disrespectful mode of delivery of negative feedback (especially 'yelling' which was a repeated complaint and clearly a major source of pain and resentment), inconsistent application of rules, lack of confidentiality and privacy, and valuing of some gifts or competencies above others.

I feel like [the teacher] abuses her power... Like with me she kind of bullies (C311A).

At school there's all these "You do this, do this, do this" and there's not "We want to do this and do it in a different way" (A43A).

Forms of disrespect from people other than teachers included friends or peers putting students down or degrading them, gossiping and criticising, and parents having too high expectations or treating students 'as a child'.

Opportunities for recognition, misrecognition and non-recognition lie in the conversational spaces, talking, listening and hearing, which are fundamental to relationships and a vehicle for recognition. Both students and teachers indicated that conditions for conversation, and recognition via conversation, are not consistent or always even evident. Teachers were aware of the importance of structures in schools that facilitate relationships and provide opportunities for conversation and acts of recognition: for example, home room time, vertical forms, or pastoral care time. However, there was clearly tension for teachers in using these structures for conversation and relationship-building in light of the pressures they work under and the time required for other 'house-keeping' duties. Teachers talked of how they 'forget sometimes to listen or just be', of having to 'force myself' or 'make the effort' to listen to students. They also described how rules can 'get in the way,' when regulatory processes are followed rather than gaining a deeper understanding of a situation.

Teachers' own experiences of recognition and misrecognition by colleagues and those in leadership can offer a bridge to understanding students' struggles over recognition and experiences of misrecognition. Students placed importance on receiving love and 
care from significant others, on having needs met, rights respected, having equality and voice, being cared for, being listened to and having someone to talk to. In an almost parallel way, teachers discussed the importance for themselves of collegial support and supportive leadership, and feeling appreciated and valued for the contribution they make at school. The matter of whether and how teacher wellbeing impacts on student wellbeing was very evident in the teacher interviews. Teachers were unambiguous in their views about the impact of increased expectations and accountability on their own wellbeing. They expressed concerns about other teachers who are unable or unwilling to 'walk the extra mile' for their students. They also believed that students tune in to when teachers are having a bad day or things are not well for them, which was echoed in students' comments expressing empathy, and in reports that a teachers' bad day impacts on them too.

\section{Conclusion}

In public policy, schools are seen primarily as instruments for producing a future workforce, their success measured by exam results. However, despite this instrumental, vocationalist orientation, schools are increasingly being recognised as key sites for promoting the wellbeing of children and young people (Hamilton and Redmond, 2010; Wyn, 2007). It is clear from this research, and from others (Bingham, 2001; Watson et al., 2012) that for both students and teachers schools are also places for important interpersonal relationships; our initial finding, that wellbeing is primarily seen by participants in relational terms, should come as no surprise. As Bingham puts it, 'human beings need something from one another when they come to places like schools' (2001: 9). Other wellbeing studies with children and young people in school contexts have also pointed out the key role that relationships play (Duckett, Sixsmith and Kagan, 2008; Soutter, 2011). However, our participants also told us that what they need most of all from these relationships was recognition. Students needed to be known personally, to be cared for as unique individuals, to be respected as persons on a basis of equality, and to be valued for their achievements and contributions. They needed this from their teachers, from their fellow students, and from their families. These elements were implicit in what they said from the start, and made explicit once those concepts of recognition theory had been introduced into 
the discussions. With some important differences, teachers also understood students' needs in similar ways.

In applying Honneth's theory of recognition to this research setting, it was not our aim to test his entire theory of social development, but rather to explore the usefulness and relevance of key concepts: specifically the three modes of recognition, and secondarily the idea that experiences of misrecognition can be the motor of struggle. Of the latter we saw only glimpses in this research, and more work in depth would be necessary to develop this further. ${ }^{4}$

What was striking in this research was how strongly the three specific modes of recognition proposed in Honneth's model, expressed by him as love, rights and solidarity and translated here as cared for, respected and valued, resonate with students' and teachers' experience and understanding of how relationships play out in the school environment. Looking at recognition, at relationships and ultimately at wellbeing through this lens enables us to understand them in a way that is holistic and at the same time takes account of important distinctions. If a student is cared for as an individual with needs but not respected as someone with rights, or is valued for their work but not loved for who they are, then we can see how recognition, in such cases, coexists with misrecognition. This, then, is an analytic framework that can not only assist sociological researchers to understand what is going on in a school setting, but can help teachers, school managers and policy-makers to improve the school environment for all members. Because the concept of recognition is intersubjective and reciprocal, it can also direct attention to the ways in which students recognise or misrecognise each other, and indeed their teachers.

Honneth pays little attention to schools in his account of 'the moral grammar of social conflicts'. As Van den Brink (2013) points out, this is a particular lacuna in his recent account of 'the social foundations of democratic life' (Honneth 2014), because the school is arguably at least as important as the family in laying those foundations. $\mathrm{He}$

\footnotetext{
${ }^{4}$ Bingham's (2001) work is illuminating in this regard, although he draws more on Taylor's (1994) theory of recognition in multicultural settings than on Honneth's.
} 
does address 'education and the public sphere' in a recent article (Honneth 2012b), not so far published in English. It is not possible on the basis of this research to develop a full account of how schools as institutions could feature in his broader theoretical framework. What can be said, at least tentatively, is that schools appear to be important sites for struggles over recognition, and that - occupying as they do a space somewhere between the intimate setting of the family and the public sphere, regulated by the state and featuring complex networks of relationships - those struggles may relate to any and all of the three modes of recognition.

In the world of theory, these intimations deserve further exploration. In the world of practice, they have already proved to have resonance. The school boards who partnered this research are already looking at how they can implement the insights from this research in developing their strategies for promoting wellbeing. Recognition theory offers a powerful tool for normative evaluation of how a social institution (in this case a school) should be organised so that everyone enjoys the recognition due to them. The use of recognition theory in this study allows for a deeper examination of the social conditions necessary for formation of identity, wellbeing and resilience, including love and relationship (crucial for self-confidence), human dignity (selfrespect) and individuals' capacities, achievements and potential contribution to social life (self-esteem) (Graham and Fitzgerald, 2010). Such an approach leads to important questions such as: To what extent is a school a community of shared identities and interests? To what extent does a school provide effective spaces for love, rights and solidarity? What are the cultural or structural barriers to different forms of recognition: for example, is there a culture that allows children to assert their rights when adults may be over-focused on their needs; and what is the relationship between authority, power and recognition of achievement? Is 'recognition' a concept that can be authentically integrated into educational policy, culture and practice?

None of these issues is entirely straightforward; recognition is not a pure and unadulterated good of which we all simply aim to get as much as we can. Love and care can be experienced as oppressive; rights can come into sharp conflict with each other; esteem can be felt to be false or undeserved, and may be complicated by issues 
of competition or authority (McBride, 2013). Hence the ways in which recognition might be reflected in policy and practice are problematic. While Phase 1 of this study pointed to potential avenues for promoting recognition via the different policy domains (references to the development of caring, supportive relationships and a 'caring culture', opportunities for participation, student voice or 'having a say', and practices that value diversity and recognise unique individual attributes), the student and teacher findings suggest that closer attention needs to be given to ways in which the three dimensions of recognition can be integrated and explicitly attended to in education policy.

\section{References}

Aggleton P, Dennison C and Warwick I (2010) Promoting Health and Wellbeing Through Schools. London: Routledge.

Amerijckx G and Humblet C (2014) Child-wellbeing: What does it mean? Children and Society 28: 404-415.

Anderson, D.L. and Graham, A. (In press) Improving student wellbeing: Having a say at school. School Effectiveness and School Improvement. Published online 05 Oct 2015, DOI: 10.1080/09243453.2015.1084336

ASPA (2008) Policy Position Statement: Student Wellbeing. Kingston, ACT: Australian Secondary Principals Association.

Ben-Arieh A (2006) Measuring and Monitoring the Well-Being of Young Children Around the World. Paper commissioned for the EFA Global Monitoring Report 2007 - Strong Foundations: Early Childhood Care and Education.

Bingham C (2001) Schools of Recognition: Identity Politics and Classroom Practices, Lanham: Rowman and Littlefield.

Bourke L and Geldens P (2007) What does wellbeing mean? Perspectives of wellbeing among young people and youth workers in rural Victoria. Youth Studies Australia 26: 41-49.

Camfield L, Streuli N and Woodhead M (2009) What's the use of 'well-being' in contexts of child poverty? Approaches to research, monitoring and children's participation. The International Journal of Children's Rights 17: 65-109. 
DEEWR (2011) National Safe Schools Framework Resource Manual. Canberra: Australian Government Department of Education, Employment and Workplace Relations.

Duckett, P., Sixsmith, J. and Kagan, G. (2008) Researching Pupil Well-Being in UK Secondary Schools: Community psychology and the politics of research. Childhood 15(1): 89-106

Fattore T, Mason J and Watson E (2007) Children's conceptualisation(s) of their wellbeing. Social Indicators Research 80: 5-29.

Fitzgerald R, Graham A, Smith A and Taylor N (2010) Children's participation as a struggle over recognition: Promise of dialogue. In: Percy-Smith B and Thomas $\mathrm{N}$ (eds) A Handbook of Children and Young People's Participation: Perspectives from Theory and Practice. London: Routledge.

Fraser N (1995) From redistribution to recognition?: Dilemmas of justice in a 'postsocialist' age. New Left Review 212: 68-93.

Gillett-Swan JK (2014) Investigating tween children's capacity to conceptualise the complex issue of wellbeing. Global Studies of Childhood 4: 64-76.

Graham A, Shipway B and Fitzgerald RM (2009) Australian children's perspectives on rights, responsibilities, and citizenship: Implications for teacher practice and citizenship education In: Taylor NJ and Smith AB (eds) Children as Citizens? International Voices. Otago, New Zealand Otago University Press.

Graham A and Fitzgerald R (2010) Progressing children's participation: Exploring the potential of a dialogical turn. Childhood 17(3), 343-359.

Graham A, Fitzgerald R, Powell M, Thomas N, Anderson D, White N and Simmons C (2014a) Improving approaches to wellbeing in schools: What role does recognition play? Final Report: Volume One. Centre for Children and Young People, Southern Cross University, Lismore.

Graham A, Fitzgerald R, Powell M, Thomas N, Anderson D, White N and Simmons C (2014b) Improving approaches to wellbeing in schools: What role does recognition play? Final Report: Volume Two. Centre for Children and Young People, Southern Cross University, Lismore. 
Hamilton M and Redmond G (2010) Conceptualisation of Social And Emotional Wellbeing for Children and Young People, and Policy Implications. Sydney: Social Policy Research Centre.

Honneth A (1995) The Struggle for Recognition: The Moral Grammar of Social Conflicts, Cambridge: Polity Press.

Honneth A (2007) Between justice and affection: The family as a field of moral disputes In: Honneth A (ed) Disrespect: The Normative Foundations of Critical Theory. Cambridge: Polity.

Honneth A (2012a) The I in We: Studies in the Theory of Recognition, Cambridge: Polity.

Honneth, A (2012b) Erziehung und demokratische Öffentlichkeit. Ein vernachlässigtes Kapitel der politischen Philosophie. Zeitschrift für Erziehungswissenschaft 15: 429-442.

Honneth A (2014) Freedom's Right: The Social Foundations of Democratic Life, Cambridge: Polity.

Houston S and Dolan P (2008) Conceptualising child and family support: The contribution of Honneth's critical theory of recognition. Children \& Society 22: 458-469.

Johnson B (2008) Teacher-student relationships which promote resilience at school: A micro-level analysis of students' views. British Journal of Guidance \& Counselling 36: 385-398.

McAuley C and Rose W (2010) Child Well-being: Understanding Children's Lives. London: Jessica Kingsley Publishers.

McBride C (2013) Recognition, Cambridge: Polity Press.

MCEETYA (2008) Melbourne Declaration on Educational Goals for Young Australians. Melbourne: Ministerial Council on Education Employment Training and Youth Affairs.

Munn P (2010) How schools can contribute to pupils' well-being. In: McAuley C and Rose W (eds) Child Well-Being: Understanding Children's Lives. London: Jessica Kingsley Publishers. 
Prout A and James A (1990) A new paradigm for the sociology of childhood. In: James A and Prout A (eds) Constructing and Reconstructing Childhood: Contemporary Issues in the Sociological Study of Childhood. Basingstoke: Falmer Press.

Redmond G, Skattebol J and Saunders P (2013) The Australian Child Wellbeing Project: Overview [Draft]. Australian Child Wellbeing website: Flinders University, the University of New South Wales, and the Australian Council for Educational Research (http://australianchildwellbeing.com.au/).

Simmons, C, Graham, A and Thomas, N (2015) Imagining an ideal school for wellbeing: Locating student voice, Journal of Educational Change, 16, 129144.

Sixsmith J, Gabhainn S, Fleming C, and O’Higgins S (2007) Children's, parents' and teachers' perceptions of child wellbeing. Health Education 107: 511-523.

Skattebol J, Hamilton M, Skrzypiec G, et al. (2013) Understanding Children's Perspectives on Wellbeing: Phase 1 Report Australian Child Wellbeing Project.

Soutter, A (2011) What can we learn about wellbeing in school? Journal of Student Wellbeing 5(1): 1-21.

Stratham J and Chase E (2010) Childhood Wellbeing: A Brief Overview. London: Childhood Wellbeing Research Centre, Briefing Paper 1.

Taylor C (1994) The politics of recognition. In: Gutmann A (ed) Multiculturalism: Examining the Politics of Recognition Princeton Princeton University Press.

Thomas N (2012) Love, rights and solidarity: Studying children's participation using Honneth's theory of recognition. Childhood 19: 453-466.

Thompson S (2006) The Political Theory of Recognition, Cambridge: Policy Press.

UNICEF (2007) Child Poverty in Perspective: An Overview of Child Well-Being in Rich Countries. Florence: UNICEF.

Van den Brink B (2013) From Personal Relations to the Rest of Society. Krisis (www.krisis.eu/) 
Van den Brink B and Owen D (2007) Recognition and Power: Axel Honneth and the Tradition of Critical Social Theory. Cambridge: Cambridge University Press.

Warming H (2006) 'How can you know? You're not a foster child': Dilemmas and possibilities of giving voice to children in foster care. Children, Youth and Environments 16: 28-50.

Watson D, Emery C and Bayliss P (2012) Children's Social and Emotional Wellbeing in Schools: A Critical Perspective, Bristol: Policy Press.

Wyn, J (2007) Learning to 'become somebody well': Challenges for educational policy. The Australian Educational Researcher 34(3): 35-52. 